\title{
Comparison of 3D scanning versus traditional methods of capturing foot and ankle morphology for the fabrication of orthoses: a systematic review
}

\author{
Muhannad Farhan ${ }^{1,2,3^{*}}$ D, Joyce Zhanzi Wang ${ }^{1,2}$, Paula Bray ${ }^{2}$, Joshua Burns ${ }^{1,2}$ and Tegan L. Cheng ${ }^{1,4}$
}

\begin{abstract}
Background: In the production of ankle-foot orthoses and in-shoe foot orthoses, lower leg morphology is traditionally captured using a plaster cast or foam impression box. Plaster-based processes are a time-consuming and labour-intensive fabrication method. 3D scanning is a promising alternative, however how these new technologies compare with traditional methods is unclear. The aim of this systematic review was to compare the speed, accuracy and reliability of 3D scanning with traditional methods of capturing foot and ankle morphology for fabricating orthoses.

Methods: PRISMA guidelines were followed and electronic databases were searched to March 2020 using keywords related to 3D scanning technologies and traditional foot and ankle morphology capture methods. Studies of any design from healthy or clinical populations of any age and gender were eligible for inclusion. Studies must have compared 3D scanning to another form of capturing morphology of the foot and/or ankle. Data relating to speed, accuracy and reliability as well as study design, 3D scanner specifications and comparative capture techniques were extracted by two authors (M.F. and Z.W.). Study quality was assessed using the Grading of Recommendations, Assessment, Development and Evaluations (GRADE) and Consensus-Based Standards for the Selection of Health Measurement Instruments (COSMIN).

Results: Six articles met the inclusion criteria, whereby 3D scanning was compared to five traditional methods (plaster cast, foam impression box, ink footprint, digital footprint and clinical assessment). The quality of study outcomes was rated low to moderate (GRADE) and doubtful to adequate (COSMIN). Compared to traditional methods, 3D scanning appeared to be faster than casting (2 to $11 \mathrm{~min}$ vs 11 to $16 \mathrm{~min}$ ). Inter-rater reliability (ICC 0.18-0.99) and intra-rater reliability (ICCs $0.25-0.99$ ) were highly variable for both 3D scanning and traditional techniques, with higher agreement generally dependent on the foot parameter measured.

(Continued on next page)
\end{abstract}

\footnotetext{
* Correspondence: mfar2149@uni.sydney.edu.au

'Engineering Prototypes \& Implants for Children (EPIC) Lab, The Children's Hospital at Westmead, Sydney, NSW, Australia

2University of Sydney School of Health Sciences \& Children's Hospital at

Westmead, Westmead, Sydney, NSW 2145, Australia

Full list of author information is available at the end of the article
}

\section{$\triangle B M C$}

(c) The Author(s). 2021 Open Access This article is licensed under a Creative Commons Attribution 4.0 International License, which permits use, sharing, adaptation, distribution and reproduction in any medium or format, as long as you give appropriate credit to the original author(s) and the source, provide a link to the Creative Commons licence, and indicate if changes were made. The images or other third party material in this article are included in the article's Creative Commons licence, unless indicated otherwise in a credit line to the material. If material is not included in the article's Creative Commons licence and your intended use is not permitted by statutory regulation or exceeds the permitted use, you will need to obtain permission directly from the copyright holder. To view a copy of this licence, visit http://creativecommons.org/licenses/by/4.0/ The Creative Commons Public Domain Dedication waiver (http://creativecommons.org/publicdomain/zero/1.0/) applies to the data made available in this article, unless otherwise stated in a credit line to the data. 
(Continued from previous page)

Conclusions: The quality and quantity of literature comparing the speed, accuracy and reliability of 3D scanning

with traditional methods of capturing foot and ankle morphology is low. 3D scanning appears to be faster

especially for experienced users, however accuracy and reliability between methods is variable.

Keywords: 3D scanning, Lower limb, Lower extremity, Impression, Orthoses, Orthotic devices

\section{Introduction}

Orthoses are external supportive devices that are worn to reduce pain and enhance the function of patients with disorders of the neuromuscular and/or musculoskeletal systems. The most common types of orthoses are hand splints, spinal bracing, in-shoe foot orthoses (FO), and ankle-foot orthoses (AFO). FOs are used to support and accommodate the foot to avoid or correct foot deformities, help to maintain uniform body weight distribution and improve foot function as well as reduce pain. AFOs aim to regulate the movement of the ankle, compensate for weakness, heel misalignment and control deformities. AFOs are also used to improve toe clearance, maintain a neutral position and resist contracted muscles of the ankle and foot during gait.

Traditional manufacturing of foot and ankle orthoses is cumbersome and involves labour intensive manual production methods [1]. Fabrication of FOs involves first forming the negative impression, such as pressing the plantar surface of the foot into a foam box or draping the foot using plaster of Paris. The negative impression is filled with plaster to generate the positive model and manually modified by the clinician. After placing the positive model on the vacuum table, it is wrapped with heated thermoplastic sheet and moulded to the geometry of the model by applying a vacuum. Similarly, AFOs are generally hand made from plaster casting the patient's lower leg. The negative cast is filled with fluid plaster of Paris to form a positive model, which is modified manually by adding or removing plaster. This modified positive is then vacuum formed with polypropylene to produce an AFO $[2,3]$. These traditional methods of capturing foot and ankle morphology can be highly resource intensive, especially for fabricating AFOs, requiring dedicated infrastructure including a casting room, plaster friendly furniture, sink with plaster capture, and anti-slip floor. For departments or practices that have only one casting room and several clinicians, room availability can present logistical difficulties and increased patient wait-times. In addition, storage of consumables, such as foam impression boxes and plaster rolls, requires a dry area that can occupy a large space. Positive plaster casts are heavy and need to be handled carefully to prevent breakage that would require recasting the patient. After fabricating either FOs or AFOs, the positive cast is destroyed to provide storage space for new casts, which prevents duplication of the same prescription from an old cast. Although casting for FOs may not require the same level of resourcing as AFOs, the process is still highly dependent on practitioner experience of positioning and manipulating the foot and/or ankle [4]. Overall, these traditional methods are labour intensive, restrict design choices, and require high level of skill and dedicated infrastructure that can increase costs and patient wait times $[5,6]$.

Digital approaches are emerging as alternative plasterless fabrication methods, which have the potential to reduce long lead times, material wastage, and cost $[5,7]$. Digital fabrication requires the input of foot and ankle morphology, which can be obtained by 3D scanning the foot and ankle directly or by scanning a negative impression. The digitised data can be used to create a 3D model of the patient and/or their device [8]. Computer Aided Design (CAD) software is used to process the 3D scan, where adjustments can be made to the geometry [9]. The resulting 3D model of the modified positive model or final orthotic design can then be exported to either a milling machine or a 3D printer $[10,11]$.

Recently, 3D scanners have been developed to improve the production of orthoses and prostheses [12, 13]. Using 3D scanning provides clinicians with flexibility as to where they are taking impressions (e.g. on ward or in fitting rooms or in the community). 3D scanning technology would also minimise plaster storage requirements and enable exact duplication of a prescription. In a digital fabrication workflow, the accurate and reliable input of a patient's lower leg morphology is critical for an appropriately fitting device. However, commercially available scanners have varying speed, accuracy and reliability that need to be investigated. Therefore, the aim of this systematic review was to compare the speed, accuracy and reliability of 3D scanning with traditional methods of capturing foot and ankle morphology for fabricating orthoses.

\section{Methods and materials}

\section{Systematic literature search}

We followed the Preferred Reporting Items for Systematic Reviews and Meta-Analyses (PRISMA) checklist to conduct the systematic review [14]. The search strategy focused on terms comparing 3D scanning with other traditional morphology capture methods of the foot and/ 
or ankle. The focus was to cover all possible methods for capturing the morphology of the foot and ankle. For example, plaster casting and foam impression boxes could be used to capture the foot and ankle to produce AFOs, FOs or footwear.

Search terms related to the 3D scanning (3D scan*, Photogrammetry, Laser scan*, Structured Light scan*, Three dimensional scan*, (3D digitalization or 3D digitalisation), Three-dimensional construction, 3D surface scan $^{*}, 3 \mathrm{D}$ laser scan*, 3D structured light scan*, scan*) combined with AND to search terms related to foot and/or ankle (ankle, foot, Foot morphology, (ankle and foot), ankle morphology, foot parameter*, ankle parameter*) also combined with AND to search terms related to foot and ankle capturing methods other than 3D scanning (Plaster cast*, foam impression, polyurethane resin, (fiber* cast* or fibre* cast*), (orthopedic cast* or orthopaedic cast*), cast*, (Plaster Mold* or plaster Mould), (mold* or mould), Hand cast*, (cast* adj4 ankle), (cast* adj4 foot), fiberglass cast*, cast* socks, negative impression, positive impression, foot trace*, foot print", footprint). Electronic database searches were carried out in ProQuest Central, MEDLINE (via OvidSP), EMBASE, Scopus, AMED (via OvidSP), Web of Science and CINAHL (via EBSCO). The search keywords were designed for MEDLINE and adapted for other databases. No restrictions were added to the search, such as language or date (Additional file 1).

\section{Eligibility criteria}

All studies comparing 3D scanning to other foot and/or ankle capture methods were eligible for review and were included regardless of date of article publication, language, participant age or demographics. Reviews, conference reports and newspaper articles were excluded, as these are rarely peer-reviewed and may only present preliminary or limited data.

\section{Study selection and data extraction}

After deletion of duplicates, the titles and abstracts of included studies were assessed and screened by authors M.F. and Z.W. based on eligibility criteria in the first pass. Following this, the full-text articles were retrieved by the researchers to assess eligibility for inclusion independently (second pass). In case of disagreement, author J.B. was asked to evaluate the article and all discrepancies were resolved. The included articles underwent data extraction by authors M.F. and Z.W. independently who then compared the extractions for accuracy and completeness. Extraction of data comprised of study design, sample size, demographic characteristics, information about the 3D scanner and scanning methods, and comparative foot/ankle capture techniques.
Study outcomes of time, accuracy and reliability were extracted. For the purposes of this review, we considered speed as the time required to obtain the foot and/or ankle morphology, accuracy as the relationship between the scanned measurements to the patient's clinical measurements, and reliability as the consistency and repeatability of the capture method. The reported ICCs were classified as poor (less than 0.50), moderate (between 0.50 to 0.75 ), good (between 0.75 to 0.90 ) or excellent (greater than 0.90) [15].

\section{Study quality}

The evidence level of each study was assessed using the Oxford Centre for Evidence-Based Medicine 2011 Levels of Evidence (OCEBM Levels) rating from level one to level five, where level one representing a randomised controlled design and highest level of evidence [16]. The methodological and quality of the assessment measures reported in the included studies were rated using version one of the Consensus-Based Standards for the Selection of Health measurement Instrument (COSMIN) [17-19]. The reported instruments were assessed using three measurement properties from the COSMIN checklist: content validity, reliability and measurement error [20]. These three items from the COSMIN checklist were used as they were the most relevant to the aims of this review. COSMIN is the gold standard for patient reported outcome measurement evaluation, however more recently it has been applied to clinician-rated assessments $[17,20,21]$. Studies that evaluated or reported the efficacy of an intervention were assessed using the Grading of Recommendations Assessment, Development, and Evaluation (GRADE) approach [22] utilising GRADEpro GDT. The GRADE approach was used to assess the strength and certainty of the overall evidence reported in the included studies in this review.

\section{Meta-analysis}

We attempted meta-analysis on pooled measurements of foot parameters collected from 3D scanning and traditional methods. Three studies [23-25] provided raw measurements for parameters of the foot such as arch height, rearfoot width and forefoot width. However, due to heterogeneity in data capture methods we were unable to conduct the meta-analysis (Additional file 2).

\section{Results}

\section{Description of included studies}

The original electronic database search led to a total of 2897 articles with 2525 publications remaining after eliminating duplicates. After completing the title and abstract evaluation, full-text articles were downloaded for 26 publications. After screening and analysing the article's full text, only five met the inclusion criteria and 
were included in this review (Fig. 1). One additional article was found after a hand search of the references. The six studies included one randomised controlled trial evaluating AFOs [26], four studies reporting reliability and accuracy of 3D scanning for FOs [23-25, 27], and two studies assessing speed of 3D scanning for FOs and AFOs $[25,28]$ (Table 1). Traditional foot and ankle capture tools included in the studies were plaster cast, foam impression, digital footprint, ink footprint and 3D scanning. The 3D scanning technologies found in this systematic review included laser 3D scanners (Table 1).

\section{Participant characteristics}

The six studies included 189 adults (102 female, 86 male, and 1 unspecified) $[23-25,27,28]$ and 134 children (59 girls, 75 boys) [23, 24, 26, 27]. The mean age and SD of the participants in the included studies were 23.8 years, SD 3.6 [23], 35.4 years, SD 13.6 [24], 42.8 years, SD 11.4 [27], males 21.2 years, SD 2.1 and females 21 years SD 5.9 [25], males 10.7 years SD 4.9 females 9.8 years SD 4.1 [26] and not reported [28]. The sample size for the studies were $n=15$ [23], $n=21$ [24], $n=22$ [27], $n=130$ [25], $n=134$ [26] and $\mathrm{n}=1$ [28]. Five studies included healthy

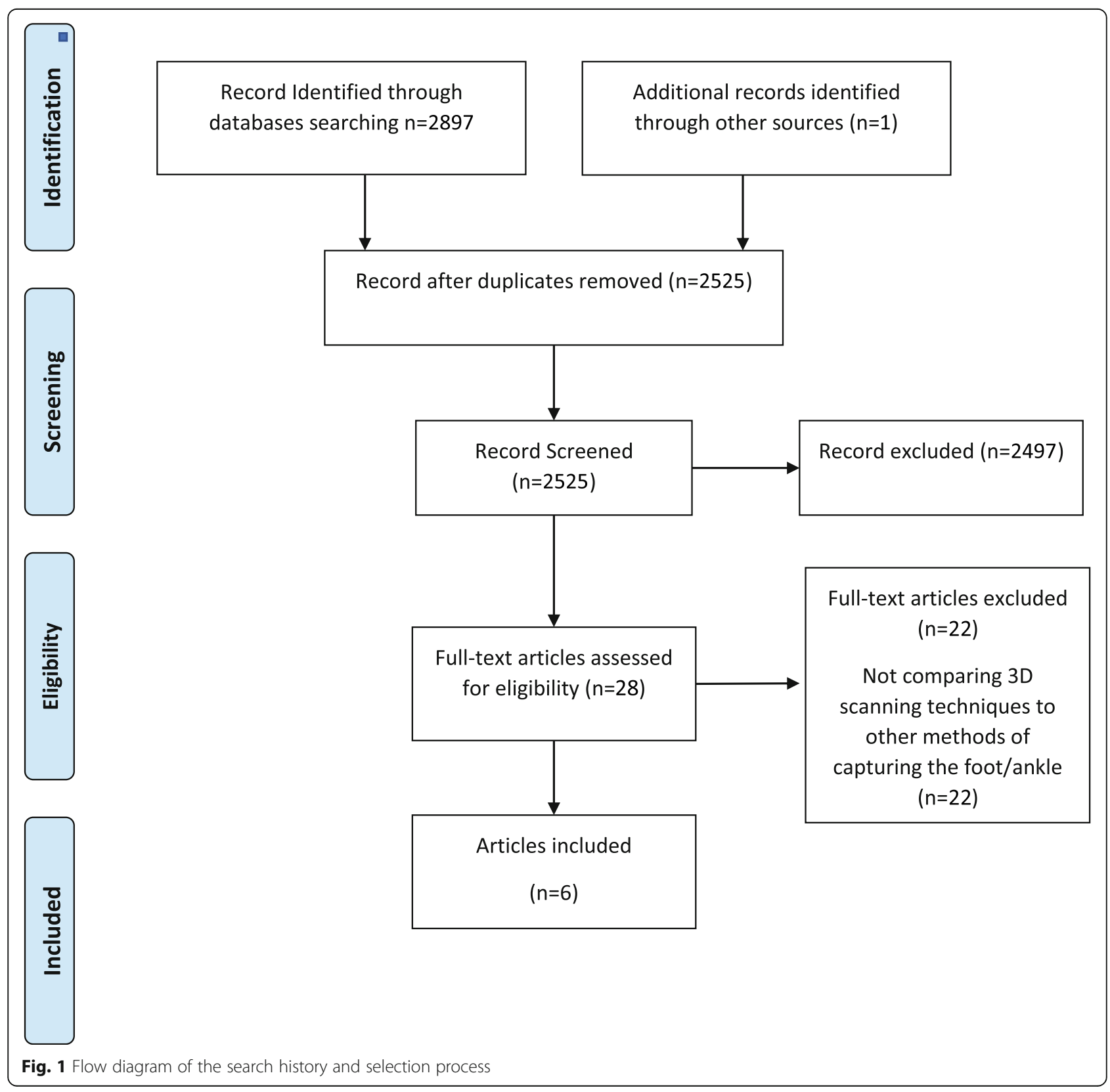


Table 1 Participant characteristics and outcomes of included studies

\begin{tabular}{|c|c|c|c|c|c|c|c|c|}
\hline Reference & $\begin{array}{l}\text { Participant } \\
\text { characteristics }\end{array}$ & $\begin{array}{l}\text { Orthotic } \\
\text { device }\end{array}$ & $\begin{array}{l}\text { Comparison } \\
\text { methods and } \\
\text { weightbearing } \\
\text { status }\end{array}$ & $\begin{array}{l}\text { 3D scanner } \\
\text { name and } \\
\text { technology }\end{array}$ & $\begin{array}{l}\text { 3D scan } \\
\text { position and } \\
\text { weightbearing } \\
\text { status }\end{array}$ & Outcomes & $\begin{array}{l}\text { Main result and } \\
\text { authors } \\
\text { conclusions }\end{array}$ & $\begin{array}{l}\text { OCEBM } \\
\text { level }\end{array}$ \\
\hline $\begin{array}{l}\text { Roberts, } \\
\text { et al. } 2016 \\
{[26]}\end{array}$ & $\begin{array}{l}N=136 \text { aged }<21 \text { yrs., } \\
\text { prescribed rigid and/ } \\
\text { or hinged AFOs (10.7 } \\
\text { SD } 4.9 \text { yrs. for males, } \\
9.8 \text { SD } 4.1 \text { yrs. for } \\
\text { females) }\end{array}$ & AFO & $\begin{array}{l}\text { Plaster cast, } \\
\text { casting position } \\
\text { and } \\
\text { weightbearing } \\
\text { status not } \\
\text { described }\end{array}$ & $\begin{array}{l}\text { 3D FastSCAN } \\
\text { (Laser } \\
\text { scanner) }\end{array}$ & $\begin{array}{l}\text { Position and } \\
\text { weightbearing } \\
\text { status not } \\
\text { described }\end{array}$ & $\begin{array}{l}\text { 1) Secondary } \\
\text { outcome } \\
\text { measures time } \\
\text { (min) spent with } \\
\text { subjects to cast } \\
\text { and scan limbs }\end{array}$ & $\begin{array}{l}\text { 1) Orthotists } \\
\text { experienced in 3D } \\
\text { scanning had a } \\
\text { significant time } \\
\text { reduction } \\
\text { compared to } \\
\text { casting }\end{array}$ & 2 \\
\hline $\begin{array}{l}\text { Carroll, } \\
\text { et al. } 2011 \\
{[24]}\end{array}$ & $\begin{array}{l}N=21 \text { aged }>20 \text { yrs., } \\
\text { healthy participants } \\
\text { (35.4 SD 13.6yrs) }\end{array}$ & $\mathrm{FO}$ & $\begin{array}{l}\text { Plaster cast, } \\
\text { NWB (sitting) }\end{array}$ & $\begin{array}{l}\text { Name not } \\
\text { provided } \\
\text { (3D non- } \\
\text { contact } \\
\text { digitiser) }\end{array}$ & NWB (sitting) & $\begin{array}{l}\text { 1) ICC for intra } \\
\text { and inter-rater } \\
\text { reliability } \\
\text { 2) Measurement } \\
\text { error assessed by } \\
\text { smallest real } \\
\text { difference }\end{array}$ & $\begin{array}{l}\text { 1) } 3 D \text { scanning is } \\
\text { reliable with } \\
\text { reduced } \\
\text { measurement } \\
\text { variability } \\
\text { 2) Smallest real } \\
\text { differences } \\
\text { consistent between } \\
\text { the raters and } \\
\text { casting technique }\end{array}$ & 3 \\
\hline $\begin{array}{l}\text { Laughton, } \\
\text { et al. } 2002 \\
\text { [23] }\end{array}$ & $\begin{array}{l}N=15 \text { aged } 20-34 \\
\text { yrs., free of lower- } \\
\text { extremity injuries ( } 23.8 \\
\text { SD } 3.6 \text { yrs) }\end{array}$ & $\mathrm{FO}$ & $\begin{array}{l}\text { 1) Plaster cast, } \\
\text { NWB (lying } \\
\text { prone) } \\
\text { 2) Foam } \\
\text { impression, PWB } \\
\text { (sitting) }\end{array}$ & $\begin{array}{l}\text { Sharp Shape } \\
\text { (Laser } \\
\text { scanner) }\end{array}$ & $\begin{array}{l}\text { 1) } P W B \text {, (sitting) } \\
\text { 2) NWB, (lying } \\
\text { prone) }\end{array}$ & $\begin{array}{l}\text { 1) Reliability as } \\
\text { assessed by } \\
\text { within-method } \\
\text { ICCS } \\
\text { 2) ICCs between } \\
\text { clinical measures } \\
\text { and the four } \\
\text { methods }\end{array}$ & $\begin{array}{l}\text { 1) Methods differ in } \\
\text { reliability } \\
\text { 2) Accuracy of foot } \\
\text { measures are } \\
\text { influenced by the } \\
\text { method used }\end{array}$ & 3 \\
\hline $\begin{array}{l}\text { Telfer, } \\
\text { et al. } 2012 \\
{[27]}\end{array}$ & $\begin{array}{l}N=22 \text { aged }>18 \text { yrs., } \\
\text { with non-cavus foot } \\
\text { type ( } 42.8 \text { SD } 11.4 \mathrm{yrs})\end{array}$ & $\mathrm{FO}$ & $\begin{array}{l}\text { 1) Plaster cast, } \\
\text { NWB (lying } \\
\text { prone) } \\
\text { 2) Foam box, } \\
\text { PWB (sitting) } \\
\text { 3) Foam box, } \\
\text { FWB (walking } \\
\text { into the box) }\end{array}$ & $\begin{array}{l}\text { 3D FastSCAN } \\
\text { (Laser } \\
\text { scanner) }\end{array}$ & $\begin{array}{l}\text { 1) } 50 \% \text { WB } \\
\text { (relaxed } \\
\text { standing } \\
\text { position) } \\
\text { 2) } 50 \% \text { WB } \\
\text { (Corrected } \\
\text { standing) } \\
\text { 3) PWB (sitting) }\end{array}$ & $\begin{array}{l}\text { 1) Intra- and } \\
\text { inter-rater reli- } \\
\text { ability }(\operatorname{ICC}(2,1))\end{array}$ & $\begin{array}{l}\text { 1) Apart from } \\
\text { medial arch height, } \\
\text { all methods shows } \\
\text { good-excellent } \\
\text { intra- and inter- } \\
\text { rater reliability }\end{array}$ & 3 \\
\hline $\begin{array}{l}\text { Lee, et al. } \\
2014 \text { [25] }\end{array}$ & $\begin{array}{l}N=130 \text { age } 18-30 \text { yrs., } \\
\text { Healthy participants } \\
(21.25 \text { SD } 2.15 \text { yrs. for } \\
\text { males, } 21.98 \text { SD } 2.94 \\
\text { yrs. for females) }\end{array}$ & $\begin{array}{l}\text { Not } \\
\text { described }\end{array}$ & $\begin{array}{l}\text { 1) Digital } \\
\text { calliper, 50\% WB } \\
\text { (standing) } \\
\text { 2) Ink footprint, } \\
50 \% \text { WB } \\
\text { (standing) } \\
\text { 3) Digital } \\
\text { footprint, } \\
50 \% \text { WB } \\
\text { (position) }\end{array}$ & $\begin{array}{l}\text { INFOOT USB } \\
\text { (Laser } \\
\text { scanner) }\end{array}$ & $\begin{array}{l}\text { 50\% WB } \\
\text { (position) }\end{array}$ & $\begin{array}{l}\text { 1) The mean } \\
\text { absolute } \\
\text { difference values } \\
\text { 2) ICCs for } \\
\text { precision } \\
\text { evaluation }\end{array}$ & $\begin{array}{l}\text { 1) } 3 D \text { scanning had } \\
\text { lowest mean } \\
\text { absolute difference } \\
\text { 2) Apart from ink } \\
\text { footprint, all } \\
\text { measures had ICCs } \\
\text { from good to } \\
\text { excellent }\end{array}$ & 3 \\
\hline $\begin{array}{l}\text { Payne, } \\
2007 \text { [28] }\end{array}$ & $\begin{array}{l}\text { ? - No participant } \\
\text { characteristic or } \\
\text { condition were given }\end{array}$ & FO & $\begin{array}{l}\text { Plaster cast, } \\
\text { casting position } \\
\text { and } \\
\text { weightbearing } \\
\text { status not } \\
\text { described }\end{array}$ & $\begin{array}{l}\text { Name not } \\
\text { provided } \\
\text { (Technology } \\
\text { type not } \\
\text { reported) }\end{array}$ & $\begin{array}{l}\text { Position and } \\
\text { weightbearing } \\
\text { status not } \\
\text { described }\end{array}$ & $\begin{array}{l}\text { 1) Time to 3D } \\
\text { scan and plaster } \\
\text { cast of the foot } \\
\text { by experienced } \\
\text { podiatrist and } \\
\text { student }\end{array}$ & $\begin{array}{l}\text { 1) Plaster casting } \\
\text { slower than } 3 D \\
\text { scanning, especially } \\
\text { for experienced } \\
\text { user }\end{array}$ & 5 \\
\hline
\end{tabular}

NWB non-weightbearing, PWB partial-weightbearing, FWB Full-weightbearing, 50\%WB 50\% weightbearing,

participants $[23-25,27,28]$ while only one study included participants who were prescribed with rigid and/ or hinged AFOs although their conditions were not reported [26] (Table 1).

\section{Capture methods}

All six studies compared 3D scanning to other methods of capturing foot and/or ankle morphology. Two studies compared 3D scanning with both plaster casting and foam impression [23, 27]. Three studies compared 3D scanning to plaster casting methods only [24, 26, 28]. One study compared 3D scanning measurement to digital and ink footprints as well as digital calliper measurements [25]. The included studies assessed several weightbearing positions including non-weightbearing, full weightbearing, partial weightbearing and 50\% weightbearing (Table 1). 


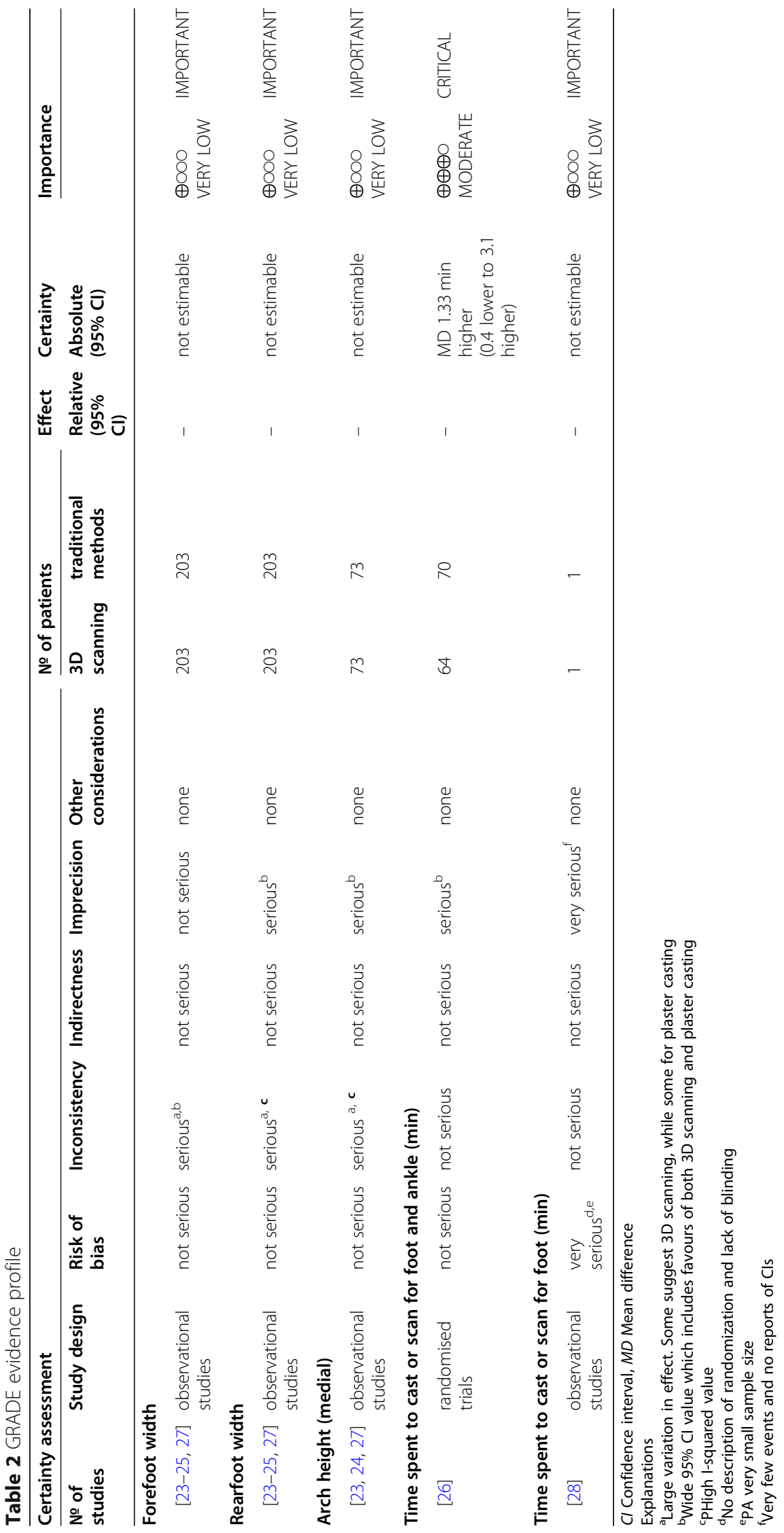


Table 3 Quality criteria for study outcomes for COSMIN. Based on Terwee et al. [29]

\begin{tabular}{llll}
\hline Property & Rating & Outcome Quality Criteria \\
\hline Criterion validity & + & Convincing arguments that criterion standard is "gold" AND correlation OR ICC with criterion standard $\geq 0.70$. \\
& $?$ & No convincing arguments that gold standard is "gold" OR no correlations OR ICC have been calculated. \\
Reliability (intra-rater, inter- & + & ICC or weighted Kappa $\geq 0.70$ OR Pearson $\gamma$ or Spearman $\rho \geq 0.80$ with evidence provided that no systematic \\
rater) & $?$ & Change has occurred. \\
& - & ICC or weighted Kappa $<0.70$ OR Pearson $\gamma$ or Spearman $\rho<0.80$, despite adequate design and method. \\
& + & SEM $<$ SDC OR SEM outside the LOA \\
Measurement error & $?$ & SEM is not defined OR doubtful design ${ }^{\mathrm{a}}$. \\
& - & SEM $\geq$ SDC OR SEM equal or inside the LOA
\end{tabular}

Abbreviation: ICC intraclass correlation coefficient, SEM standard error of measurement, SDC smallest detectable change, LOA limits of agreement ${ }^{\mathrm{a} D o u b t f u l}$ design = any essential weakness in design or execution of the study

\section{Quality of included studies}

The extracted outcomes were assessed using the GRADE process, with overall quality evidence for rearfoot width and medial arch height measurement outcomes considered very low, the forefoot width outcome considered low indicating weak evidence for reliability and accuracy (Table 2). There was a moderate level of quality for scanning and casting time for ankle and foot, showing reasonable evidence for speed. There was a very low level of quality for scanning and casting time for the foot only [28] (Table 1). Four of the studies were classified as OCEBM level 3 [23-25, 27], one was level 2 [26], and one was level 5 [28].

\section{Quality and measurement properties of included assessments}

The quality of three measurement properties included in the four studies [23-25, 27] was rated using the COSMIN checklist, reliability, measurement error and criterion validity. Based on Terwee $(21,22)$, the COSMIN checklist was rated using quality criteria (Table 3 ). The quality of outcome and measurement property were rated and shown in Table 4. Methodological quality and outcome quality of each tool was assessed using the COSMIN checklist in several measured outcomes such as forefoot, rearfoot and arch height to assess the accuracy and reliability between methods (Table 5).

Using the COSMIN checklist, the intra-rater reliability was scored moderate for weightbearing 3D scanning and digital footprint $(\mathrm{ICC}>0.70)$ and the ink footprint rating level was moderate in measuring foot parameters (ICC $>0.70$ ). The other capturing methods rated unknown for the intra-rater reliability as the methodological quality of the included studies where either inadequate or doubtful (Table 5). The measurement error and criterion validity rating level were unknown due to inadequate number of participants $N<30$ and inadequate or doubtful methodological quality (Table 5 and Additional file 3).

\section{Speed}

Two studies compared the time required to 3D scan versus plaster cast the foot and ankle (Table 6) [26, 28]. In one study, the overall time taken for 3D scanning (11.1 mins, SD 9.5) and casting (12.5 mins, SD 4.9) was similar $(p=0.056)$ [26]. However, the subset of clinicians with experience in 3D scanning were faster at 3D scanning than casting: scanning time (8.9 mins, SD 2.9) and casting (13.1 mins, SD 4.4) $(p<0.001)$ [26]. The second study compared the time for $3 \mathrm{D}$ scanning and casting both feet [28], with the bilateral foot scan taking 2 mins compared to casting taking $11 \mathrm{mins}$ for an experienced

Table 4 Levels of evidence for the quality of the measurement property for COSMIN

\begin{tabular}{|c|c|c|}
\hline Level & Rating $^{\text {a }}$ & Criteria \\
\hline Strong & $\begin{array}{l}+++ \text { or } \\
-\end{array}$ & $\begin{array}{l}\text { Consistent findings in multiple studies of adequate methodological quality OR in one study of very good methodological } \\
\text { quality. }\end{array}$ \\
\hline Moderate & ++ or - & $\begin{array}{l}\text { Consistent findings in multiple studies of doubtful methodological quality OR in one study of adequate methodological } \\
\text { quality. }\end{array}$ \\
\hline Limited & + or - & One study of inadequate methodological quality. \\
\hline Conflicting & $+/-$ & Conflicting findings. \\
\hline Unknown & $?$ & Only studies of inadequate/doubtful methodological quality. \\
\hline
\end{tabular}

${ }^{a}$ NOTE. + = positive; $=$ indeterminate; - = negative [17] 
Table 5 Assessment of the methodological quality of the studies and outcome quality of the measurement property for each method using COSMIN checklist

\begin{tabular}{lllll}
\hline Method & Reference & \multicolumn{3}{l}{ Measurement property: methodological quality per study } \\
\cline { 4 - 4 } & & Reliability & Measurement error & Criterion validity \\
\hline Casting & {$[23,24,27]$} & $?$ & $?$ \\
NWB & & & $?$ \\
Foam impression & {$[23,27]$} & $?$ & $?$ \\
PWB & {$[27]$} & $?$ & $?$ \\
FWB & & & $?$ \\
Ink footprint & {$[25]$} & $-{ }^{a}$ & $?$ \\
$50 \%$ WB & & $++^{a}$ & $?$ \\
Digital footprint & {$[25]$} & & $?$ \\
$50 \%$ WB & & $?$ & $?$ \\
3 Scanning & {$[23,24,27]$} & $?$ & $?$ \\
NWB & {$[23,27]$} & $?$ & $?$ \\
PWB & {$[27]$} & $++^{a}$ & $?$ \\
PWB (corrected position) & {$[25]$} & $?$ \\
$50 \%$ WB & & $?$ & $?$ \\
\hline
\end{tabular}

Abbreviations: NWB non-weightbearing, PWB partial-weightbearing, FWB Full-weightbearing, 50\%WB 50\%. weightbearing

Outcome Quality: += positive, $-=$ negative, ? = unknown

${ }^{a}$ One study had adequate methodological quality

clinician and 16 mins for a student (Table 6). However, this study did not report the number of participants included, standard deviation or statistical analyses.

\section{Accuracy}

One study assessed the accuracy of foot measures from 3D scans and traditional methods against clinical measurements, using ICCs [23]. Partial-weightbearing 3D scanning was found to accurately capture forefoot width (ICC 0.93) and rearfoot width (ICC 0.77), while nonweightbearing 3D scanning was accurate for forefoot width (ICC 0.84), however poor for rearfoot width (ICC 0.43). For the traditional methods, non-weightbearing plaster casting was accurate when capturing rearfoot width (ICC 0.77) and forefoot width (ICC 0.88) and partial-weightbearing foam impression was good for forefoot width (ICC 0.88), however poor for rearfoot width (ICC 0.46) [23]. Another study measured the accuracy of 3D scanning, digital footprint and ink footprints against digital caliper measurements by reporting the mean absolute difference values, finding that 3D scanning ranged between 0.6 to $11.9 \mathrm{~mm}$ while the two footprint methods ranged from 0.1 to $14.9 \mathrm{~mm}$ (no statistical analyses reported) [25].

\section{Inter-rater reliability}

Two studies reported inter-rater reliability of foot length, forefoot width, rearfoot width and medial arch height [24, 27] (Additional file 4). Carroll et al. found nonweightbearing 3D scanning demonstrated good to excellent ICC ratings $\left(\mathrm{ICC}_{3,1}\right.$ 0.81-0.99), while nonweightbearing casting measures of reliability ranged from poor to excellent $\left(\mathrm{ICC}_{3,1}\right.$ 0.57-0.99) [24]. Telfer et al. reported the position of 3D scanning affected inter-rater reliability, with relaxed standing ranging from good to excellent $\left(\mathrm{ICC}_{2,1}\right.$ 0.73-0.92), corrected standing ranging from poor to excellent $\left(\mathrm{ICC}_{2,1} 0.35-0.94\right)$ and corrected sitting ranging from good to excellent $\left(\mathrm{ICC}_{2,1}\right.$ $0.75-0.92)$. In the same study, inter-rater reliability of traditional methods also varied with position, with plaster casting ranging from poor to moderate $\left(\mathrm{ICC}_{2,1} 0.64-\right.$ 0.89 ), foam impression when sitting and walking ranging from poor to excellent $\left(\mathrm{ICC}_{2,1}\right.$ 0.41-0.91) [27].

\section{Intra-rater reliability}

Four papers reported intra-rater reliability measures of 3D scanning and traditional methods and found certain parameters of the foot were more reliably measured than others [23-25, 27] (Additional file 5). Across three studies, intra-rater reliability for foot length, forefoot width, and heel width all rated moderate to excellent for 3D scanning (ICC: 0.99 [24], 0.75-0.96 [23], and 0.87-0.96 [27]) and good to excellent for plaster casting (ICC: 0.91-0.99 [24], 0.91-0.95 [23], and 0.78-0.92 [27]) while foam impression box ranged from good to excellent (ICC: $0.93-0.95$ [23] and 0.78-0.92 [27]). Two studies found clinical experience influenced intra-rater reliability, with more experienced clinicians in 3D scanning and traditional methods resulting in higher ICC values [24, 27]. When 3D scanning, the medial arch height intra- 
rater reliability was variable, considered excellent with ICCs of 0.96-0.97 [24], poor to moderate with ICCs of 0.43-0.70 [23] and 0.25-0.64 [27]. For traditional methods, medial arch height measured through casting ranged from moderate to good (ICC: 0.65-0.87 [24], 0.67 [23], 0.70-0.73 [27]) and foam impression box was scored poor (ICC: 0.49 [23] and 0.25-0.30 [27]). Intrarater reliability for rearfoot/forefoot angle (RF/FF angle) was found to be good to excellent for 3D scanning (ICC: 0.75-0.96 [27]; 0.81-0.82 [24]; 0.65-0.79 [23]), ranged from poor to good when casting (ICC: $0.57-0.61$ [27]; 0.36-0.49 [24]; 0.59-0.83 [23]), and was rated good for foam impression box (ICC: 0.79) [23].

The fourth study reported the intra-rater reliability between four methods of capturing the plantar surface of the foot parameters (3D scanning, digital calliper, digital footprint and ink footprint) in the following parameters foot length, forefoot width, rearfoot width [25]. The study found that 3D scanning had excellent reliability (ICC: $0.95-0.98$ ), while reliability of digital callipers ranged from good to excellent (ICC: 0.74-0.98), digital footprint was excellent (ICC: 0.94-0.98) and ink foot print ranged from moderate to excellent (ICC: $0.59-$ 0.98) [25].

\section{Discussion}

In this systematic review of the literature, we identified six articles that compared 3D scanning with traditional methods of capturing morphology of the foot and/or ankle. There was moderate level evidence that 3D scanning requires less time to capture the foot and ankle when compared to traditional methods, especially for clinicians experienced in 3D scanning [26, 28]. The accuracy of 3D scanning for FOs was generally comparable with plaster casts, digital footprints and ink footprints to capture foot morphology [23, 25]. Head-to-head, 3D scanning was generally comparable in inter-rater reliability with plaster casting and foam impression as several foot parameters achieved excellent ICCs [23, 27]. The intra-rater reliability of $3 \mathrm{D}$ scanning and traditional methods was comparable with ICCs ranging between poor and excellent, however some aspects of the foot were more reliably captured than others. However, none of the included studies investigated accuracy or reliability of 3D scanning for AFOs which requires capturing lower leg, ankle as well as foot morphology. According to GRADE and COSMIN quality assessments, no study rated higher than moderate (Table 2) or adequate at best (Additional file 3) with most studies were assessed as inadequate or doubtful. Thus, there is insufficient evidence to support a clinical recommendation for the use of 3D scanning to capture the morphology of the foot and ankle (Table 5).

Two studies identified in this review reported the time required to 3D scan the foot and ankle, which is important when considering integration of digital processes into clinical workflows. Focusing on the scanning process, a study by Dessery and Pallari found that a lowcost 3D scanner (£289) was faster than a high-cost handheld scanner $(£ 13,700)$ when capturing the knee for fabricating knee orthoses [30]. However, the Dessery and Pallari study did not compare the time taken for 3D scanning with a traditional method. When considering the entire orthotic device production workflow, one of the articles in our review, reported that 3D scanning in combination with CAM produced comparable devices as traditional methods in similar time frames [26]. More recent studies have supported these findings suggesting that additive manufacturing methods are as effective as traditional methods for producing AFOs when considering time, cost and device performance [5, 31, 32]. While some evidence suggests 3D scanning may be faster than traditional methods of morphology capture, it is crucial that this does not sacrifice accuracy or reliability.

With regard to reliability of capturing foot parameters, our review found that some foot parameters, such as length and forefoot width, were reliably captured regardless of the method used. Foot arch height was the least reliable foot parameter captured by any method. This could be due to the flexibility of the arch, which makes it difficult to hold in a consistent position when casting or scanning. Laughton et al., found that foot measurements were significantly influenced by the method used to obtain foot shape [23]. Similarly, Guldemond et al., compared FOs produced by plaster cast to foam impression box and observed that each method resulted in

Table 6 Time required to cast or 3D scan the foot and/or ankle

\begin{tabular}{|c|c|c|c|c|c|}
\hline & Cast time (AFO) & & 3D Scan time (AFO) & & $p$-value \\
\hline & All user & Experienced user only & All user & Experienced user only & \\
\hline \multirow[t]{4}{*}{ Roberts A, et al. 2016 [26] } & $12.2(\mathrm{SD} 4.9) \mathrm{min}$ & & $11.1(\mathrm{SD} 9.5) \mathrm{min}$ & & $P=0.056$ \\
\hline & & 13.1 (SD 4.4) min & & 8.9 (SD 2.9) min & $P<0.001$ \\
\hline & Cast time (FO) & & 3D Scan time (FO) & & $p$-value \\
\hline & Student & Clinician & Student & Clinician & \\
\hline Payne, 2007 [28] & $16 \mathrm{~min}$ & $11 \mathrm{~min}$ & & $2 \min$ & \\
\hline
\end{tabular}


different pressure pattern and contact area [33]. Variability within capture position is significant as comfort, fitness, kinematic and kinetic function of the resulting orthotic device may be affected [34]. Too much variability in the $3 \mathrm{D}$ scanning process makes the correction of the deformity completely dependent on the rectification process, with several studies highlighting that this is a pinch point in the clinical workflow $[26,35,36]$.

The experience of the clinician affected the reliability of the 3D scan in three of the included studies [24, 26, 27 ], and was related to reducing $3 \mathrm{D}$ scanning time and variability in all foot parameters. Therefore, user training and support is critical for successful implementation of $3 \mathrm{D}$ scanning processes in a clinical environment [37]. Roberts et al., found that clinicians inexperienced in 3D scanning had the most AFO fitting problems [26]. This is supported by Wong et al., who reported that clinicians who are familiar with CAD/CAM systems were faster and less likely to have fitting issues [35]. However, the learning curve for an orthotist to reach competence with a CAD/CAM system could be up to 4 years [36]. Despite improvements in reliability and speed with experienced users, it is unclear how much experience in 3D scanning is needed to produce quality scans and how quickly this is gained. Thus, continuous assessment of scanning accuracy and reliability as well as the regular evaluation of newly available technologies are recommended.

Our review only included studies that involved the foot and ankle. Inclusion of additional regions of the body may have resulted in higher article return in our search, however these were not relevant to our research question. We also did not assess the final orthotic device that was produced by either 3D scanning or traditional methods. However, other studies assessing AFOs [38], FOs [39, 40] and scoliosis braces $[35,36,41,42]$ found comparability between 3D scanning with those manufactured traditionally in terms of fitting and device performance. Most of the studies included in this review focused on the production of FOs for healthy adult participants, which does not account for deformities (such as the need to apply corrections during scanning). Only one study in our review investigated 3D scanning in children that were prescribed AFOs. The use of 3D scanning in children can be more difficult to manage considering adherence to instructions. Thus, there is a need for more high-quality studies that examine 3D scanning for AFOs for both paediatric and adult patients with pathology. In addition, there is a growing market for commercially available 3D scanners. Our review included laser 3D scanners, however there are many more models available. Therefore, as technology improves a continual assessment of the optimum 3D scanning method and technique in terms of speed, accuracy and reliability during scanning needs to be investigated.

\section{Conclusion}

Studies comparing the speed, accuracy and reliability of 3D scanning with traditional methods of capturing the morphology of the foot and/or ankle are small and of generally low quality. With this limited evidence, 3D scanning was found to be faster than plaster casting for capturing the foot and ankle, especially for those experienced in 3D scanning. In the context of FOs, 3D scanning the foot is comparable in accuracy and reliability with traditional methods. However, this review found no evidence for the reliability or accuracy of scanning the foot and ankle for the fabrication of AFOs, an area ripe for future research.

\section{Supplementary Information}

The online version contains supplementary material available at https://doi. org/10.1186/s13047-020-00442-8.

Additional file 1:. Medline keyword list.

Additional file 2:. Variations in data provided by each study.

Additional file 3:. Assessment of the methodological quality for each study following the COSMIN checklist.

Additional file 4:. Inter-rater reliability of methods of capturing foot morphology presented as ICCS.

Additional file 5:. Intra-rater reliability of methods of capturing foot morphology presented as ICCS.

\section{Abbreviations}

3D : Three Dimensional; AFO: Ankle Foot Orthosis; CAD: Computer-Aided Design; CAM: Computer-Aided Manufacturing; COSMIN: Consensus-Based Standards for the Selection of Health Measurement Instruments; FO: Foot orthosis; GRADE: Grading of Recommendations, Assessment, Development and Evaluations; ICC: Intraclass Correlation Coefficient; PRISMA : Preferred Reporting Items for Systematic Reviews and Meta-Analyses

\section{Acknowledgements}

The authors would like to thank the University of Sydney Librarian Kanchana Ekanayake for providing advice on creating the systematic review research strategies.

\section{Authors' contributions}

All authors contributed equally in the preparation of this manuscript and approved of the final manuscript.

\section{Funding}

MF has a PhD scholarship from Saudi Arabian Cultural Mission Australia. This research project received no other funding.

Availability of data and materials

All data generated or analysed during this study are included in this published article [and its supplementary information files].

Ethics approval and consent to participate

Not applicable.

Consent for publication

Not applicable.

Competing interests

The authors declare that there are no competing interests. 


\section{Author details}

'Engineering Prototypes \& Implants for Children (EPIC) Lab, The Children's Hospital at Westmead, Sydney, NSW, Australia. ${ }^{2}$ University of Sydney School of Health Sciences \& Children's Hospital at Westmead, Westmead, Sydney, NSW 2145, Australia. ${ }^{3}$ Faculty of Medical Rehabilitation Science, Taibah University, Al Madinah Al Munawarah, Saudi Arabia. ${ }^{4}$ The University of Sydney Children's Hospital Westmead Clinical School, Faculty of Medicine and Health, The University of Sydney, Sydney, Australia.

\section{Received: 12 October 2020 Accepted: 15 December 2020}

Published online: 07 January 2021

\section{References}

1. Chen RK, Y-a J, Wensman J, Shih A. Additive manufacturing of custom orthoses and prostheses - a review. Addit Manuf. 2016;12:77-89.

2. Schrank ESBS, Stanhope SJP. Dimensional accuracy of ankle-foot orthoses constructed by rapid customization and manufacturing framework. J Rehabil Res Dev. 2011;48(1):31-42.

3. Dombroski CE, Balsdon MER, Froats $A$. The use of a low cost 3D scanning and printing tool in the manufacture of custom-made foot orthoses: a preliminary study. BMC Res Notes. 2014;7(1):443.

4. Chevalier TL, Chockalingam N. Effects of foot orthoses: how important is the practitioner? Gait Posture. 2012;35(3):383-8.

5. Totah D, Kovalenko I, Saez M, Barton K. Manufacturing choices for ankle-foot Orthoses: a multi-objective optimization. Procedia CIRP. 2017;65:145-50.

6. Houston V, Mason C, Beattie A, LaBlanc K, Garbarini M, Lorenze E, et al. The VA-Cyberware lower limb prosthetics-orthotics optical laser digitizer. J Rehabil Res Dev. 1995;32(1):55-73.

7. Wojciechowski E, Chang AY, Balassone D, Ford J, Cheng TL, Little D, et al. Feasibility of designing, manufacturing and delivering 3D printed ankle-foot orthoses: a systematic review. J Foot Ankle Res. 2019;12(1):11.

8. Wand $M$, Adams B, Ovsjanikov M, Berner A, Bokeloh M, Jenke P, et al. Efficient reconstruction of nonrigid shape and motion from real-time 3D scanner data. ACM Trans Graph. 2009;28(2):15.

9. Kobayashi T, Leung A, Hutchins S. Design and effect of ankle-foot orthoses proposed to influence muscle tone: a review. J Prosthet Orthot. 2011;23(2): $52-7$.

10. Shahar FS, Sultan MTH, Hua LS, Jawaid M, AUM S, SNA S, et al. A review on the orthotics and prosthetics and the potential of kenaf composites as alternative materials for ankle-foot orthosis. J Mech Behav Biomed Mater. 2019;99:169-85.

11. Y-a J, Plott J, Chen R, Wensman J, Shih A. Additive manufacturing of custom orthoses and prostheses-a review. Procedia CIRP. 2015;36:199-204.

12. Portnova AA, Mukherjee G, Peters KM, Yamane A, Steele KM. Design of a 3D-printed, open-source wrist-driven orthosis for individuals with spinal cord injury. PLoS One. 2018;13(2):e0193106.

13. Walbran M, Turner K, McDaid A. Customized 3D printed ankle-foot orthosis with adaptable carbon fibre composite spring joint. Cogent Eng. 2016;3(1): 1227022.

14. Moher D, Liberati A, Tetzlaff J, Altman DG. Preferred reporting items for systematic reviews and meta-analyses: the PRISMA statement. Ann Intern Med. 2009;151(4):264-9.

15. Koo TK, Li MY. A guideline of selecting and reporting intraclass correlation coefficients for reliability research. J Chiropr Med. 2016;15(2):155-63.

16. Oxford Centre for Evidence-Based Medicine 2011. OCEBM Levels of Evidence Working Group. The Oxford 2011 levels of evidence. Updated Retrieved 15th of July 2019. Availble from 42TUhttps://www.cebm.net/wpcontent/uploads/2014/06/CEBM-Levels-of-Evidence-2.1.pdfU42T.

17. Mokkink LB, De Vet HC, Prinsen CA, Patrick DL, Alonso J, Bouter LM, et al. COSMIN risk of bias checklist for systematic reviews of patient-reported outcome measures. Qual Life Res. 2018;27(5):1171-9.

18. Prinsen CA, Mokkink LB, Bouter LM, Alonso J, Patrick DL, De Vet HC, et al. COSMIN guideline for systematic reviews of patient-reported outcome measures. Qual Life Res. 2018;27(5):1147-57.

19. Terwee CB, Prinsen CA, Chiarotto A, Westerman M, Patrick DL, Alonso J, et al. COSMIN methodology for evaluating the content validity of patient-reported outcome measures: a Delphi study. Qual Life Res. 2018;27(5):1159-70.

20. Mokkink LB, Boers M, van der Vleuten CPM, Bouter LM, Alonso J, Patrick DL, et al. COSMIN risk of Bias tool to assess the quality of studies on reliability or measurement error of outcome measurement instruments: a Delphi study. BMC Med Res Methodol. 2020;20(1):293.
21. Dobson F, Hinman R, Hall M, Terwee C, Roos EM, Bennell K. Measurement properties of performance-based measures to assess physical function in hip and knee osteoarthritis: a systematic review. Osteoarthr Cartil. 2012; 20(12):1548-62.

22. Schunemann H, Brozek J, Guyatt G, Oxman A 2013. GRADE handbook for grading quality of evidence and strength of recommendations. Updated October 2013 retrieved July 15 2019. Availble from 42Thttps://gdt.gradepro. org/app/handbook/handbook.htm/42T.

23. Laughton C, Davis IM, Williams DS. A comparison of four methods of obtaining a negative impression of the foot. J Am Podiatr Med Assoc. 2002; 92(5):261-8

24. Carroll M, Annabell M-E, Rome K. Reliability of capturing foot parameters using digital scanning and the neutral suspension casting technique. J Foot Ankle Res. 2011:4:9.

25. Lee $Y-C$, Lin G, Wang M-JJ. Comparing 3D foot scanning with conventional measurement methods. J Foot Ankle Res. 2014;7(1):44.

26. Roberts A, Wales J, Smith H, Sampson CJ, Jones P, James M. A randomised controlled trial of laser scanning and casting for the construction of anklefoot orthoses. Prosthetics Orthot Int. 2016;40(2):253-61.

27. Telfer S, Gibson KS, Hennessy K, Steultjens MP, Woodburn J. Computer-aided design of customized foot orthoses: reproducibility and effect of method used to obtain foot shape. Arch Phys Med Rehabil. 2012;93(5):863-70.

28. Payne C. Cost benefit comparison of plaster casts and optical scans of the foot for the manufacture of foot orthoses. Aust J Podiat Med. 2007;41(2):29-31.

29. Terwee CB, Bot SD, de Boer MR, van der Windt DA, Knol DL, Dekker J, et al. Quality criteria were proposed for measurement properties of health status questionnaires. J Clin Epidemiol. 2007;60(1):34-42.

30. Dessery Y, Pallari J. Measurements agreement between low-cost and highlevel handheld 3D scanners to scan the knee for designing a 3D printed knee brace. PLoS One. 2018;13(1):e0190585.

31. Banga HK, Belokar RM, Kalra P, Kumar R. Fabrication and stress analysis of ankle foot orthosis with additive manufacturing. Rapid Prototyp J. 2018.

32. Mavroidis C, Ranky RG, Sivak ML, Patritti BL, DiPisa J, Caddle A, et al. Patient specific ankle-foot orthoses using rapid prototyping. J Neuroeng Rehabil. 2011;8(1):1.

33. Guldemond NA, Leffers $P$, Sanders AP, Emmen H, Schaper NC, Walenkamp GH. Casting methods and plantar pressure: effects of custom-made foot orthoses on dynamic plantar pressure distribution. J Am Podiatr Med Assoc. 2006;96(1):9-18.

34. Mündermann A, Nigg B, Humble R, Stefanyshyn D. Orthotic comfort is related to kinematics, kinetics, and EMG in recreational runners. Med Sci Sports Exerc. 2003;35:1710-9.

35. Wong M, Cheng J, Wong M, So S. A work study of the CAD/CAM method and conventional manual method in the fabrication of spinal orthoses for patients with adolescent idiopathic scoliosis. Prosthetics Orthot Int. 2005; 29(1):93-104.

36. Wong $\mathrm{M}$, Cheng C, Ng B, Lam T, Chiu S. A comparison of the clinical effectiveness of spinal orthoses manufactured using the conventional manual method and CAD/CAM method in the management of AIS. Stud Health Technol Inform. 2006;123:225.

37. Smith DG, Burgess EM. The use of CAD/CAM technology in prosthetics and orthotics-current clinical models and a view to the future. J Rehabil Res Dev. 2001;38(3):327-34

38. Banga HK, Kalra P, Belokar RM, Kumar R. Customized design and additive manufacturing of kids' ankle foot orthosis. Rapid Prototyp J. 2020;26(10): 1677-85.

39. Pallari JH, Dalgarno KW, Woodburn J. Mass customization of foot orthoses for rheumatoid arthritis using selective laser sintering. IEEE Trans Biomed Eng. 2010;57(7):1750-6.

40. Telfer $\mathrm{S}$, Woodburn J. The use of 3D surface scanning for the measurement and assessment of the human foot. J Foot Ankle Res. 2010;3(1):1-9.

41. Cottalorda J, Kohler R, Garin C, Genevois P, Lecante C, Berge B. Orthoses for mild scoliosis: a prospective study comparing traditional plaster mold manufacturing with fast, noncontact, 3-dimensional acquisition. Spine (Phila Pa 1976). 2005:30(4):399-405.

42. Wong M, Cheng J, Lo K. A comparison of treatment effectiveness between the CAD/CAM method and the manual method for managing adolescent idiopathic scoliosis. Prosthetics Orthot Int. 2005;29(1):105-11.

\section{Publisher's Note}

Springer Nature remains neutral with regard to jurisdictional claims in published maps and institutional affiliations. 